\title{
The use of JERS-1 and RADARSAT images for land use classification in the Amazon region
}

\author{
Corina da Costa. Freitas \\ Sidnei João Siqueira Sant'Anna \\ Camilo Daleles Rennó \\ INPE-DPI \\ Av. dos Astronautas 1758, 12227-010 São José dos Campos, SP-Brazil \\ Tel: +55-12-3456475, Fax: +55-12-3456468 \\ [corina,sidnei,camilo]@dpi.inpe.br
}

The objective of this paper is to compare the potential of RADARSAT and JERS- 1 images to discriminate primary forest, secondary forest and recent activities areas in Amazon. The surrounds of Tapajós National Forest (Pará State, Brazil) was used as a study site. Tonal and textural parameters were used in the analysis. It is shown that the discrimination between primary forest and secondary forest was only possible with RADARSAT image, and recent activities was better classified with the use of the JERS-1 image.

\section{INTRODUCTION}

The Brazilian tropical forest has suffered significant changes in the last decades. In 1978, a total of $1.52 \times 10^{5} \mathrm{Km}^{2}$ were deforested, rising to $5.17 \times 10^{5} \mathrm{Km}^{2}$ in 1996 [4]. Many of the forest areas were converted to pasture or agricultural areas, while many others were abandoned and are presently under regeneration. The study of these areas is important due to their impact in the carbon cycle, bio-diversity, and Amazonian forest sustainability.

Several studies have been made for mapping the secondary succession areas using remote sensing. Many of these studies are based on optical data. However, this type of data are heavily affected by atmospheric conditions (such as rain, cloud, etc.), limiting these studies specially in tropical regions. Therefore, a special attention has been given to the use of microwave remote sensing for land use monitoring. A great motivation for the use of radar data in the secondary succession studies is the sensibility of the radar backscatter signal to the vegetation structure, which is related to biomass [1], [5], [6], and [9].

In a recent work [7], using RADARSAT images, it was made a comparative study among different classifiers for three dominant classes of land cover: primary forest, secondary succession and recent activities areas (bare soil, pasture and crops). The classifications were performed over a set of bands, which were generated by filtering process. The results showed that the Iterated Conditional Modes (ICM) [3] classifier exhibited the best performance.

The principal goal of this work is to compare the discriminatory potential of the JERS-1 and RADARSAT data in classifying those three aforementioned classes throughout the results of ICM classifications. The National Forest of
Tapajós and its surrounds, Pará State, Brazil was used as study site. This region has a large variety of land cover, including primary forest, areas of secondary succession, pasture, bare soil, agricultural crops among others.

It is known that information carried by each type of data is related to the sensor characteristics and type of target imaging. The discriminatory potential is evaluated taking into account radiometric and textural information. These information were extracted using two bands of textural features (coefficient of variation and $\alpha$ parameter of K-Amplitude distribution) obtained by filtering process of the original image, and two bands of radiometric attributes (original and Frost filtered images). The results of classification were compared using the Kappa coefficient of agreement and the confusion matrices. The results showed that the $\alpha$ parameter of K-Amplitude distribution and the Frost filtered bands were the "best" textural/radiometric pair of bands for discriminating the classes. The discrimination between primary and secondary forest was only possible with the RADARSAT image, and the recent activities was better discriminated using the JERS-1 data.

\section{DATA AND METHODOLOGY}

The following images were used in this work:

- RADARSAT, from May $3^{\text {rd }}, 1996, \mathrm{C}$ band, HH polarisation, fine mode processing, amplitude, integer format (16 bits/pixel), one look, pixel spacing of $6.25 \mathrm{~m}$, incidence angle from $45^{\circ}$ to $48^{\circ}$. The spatial resolution of this image was degraded by computing the square root of the intensity mean of nine pixels ( 3 in azimuth and range), increasing the number of looks. A linear transformation was applied to this degraded image, to transform it from integer to byte format ( 8 bits/pixel). The study area (1000x1000 pixels) was extracted from this image, which is presented in Fig. la.

- JERS-1, from August $13^{\text {th }}, 1996, \mathrm{~L}$ band, HH polarisation, amplitude, integer format, three nominal looks, pixel spacing of $12.5 \mathrm{~m}$, incidence angle of $35^{\circ}$. A linear transformation was also applied to this image, in order to transform it from integer to byte format. From this image, an area of $900 \times 900$ pixels was extracted, approximately

'This work was supported by grants from PPG-7/FINEP (8808/95 and 0816/95, 6.6.96.0473.00 and 6.6.96.0474.00), CNPq (Proc. 300927/92-4). 
from the same study area of the RADARSAT image (Fig. 1c).

Fig. Ib is a Landsat/TM image, color composition 5(R), 4(G), 3(B), from 1996, from approximately the same area as radar images. This TM image is only showed here as a reference. Primary forest appears in dark green, secondary forest in light green and recent activities in magenta.

The images were filtered by the Frost filter with a window size of $5 \times 5$ pixels, in order to reduce the speckle and to verify the filtering effect on the separability of the classes. Two textural bands were built from each original image, by a filtering process, using the coefficient of variation (CV) and the $\alpha$ parameter of the $\mathrm{K}$-amplitude distribution (windows of $7 \times 7$ and $11 \times 11$ pixels, respectively).

In [7], the algorithm used to classify the RADARSAT image was the univariated ICM [8], starting with a maximum likelihood classification using distributions appropriated to radar data [2]. After classifying individually the four images, multiband classified images were obtained by Boolean operations using two individual classified images, one representing radiometric attributes (original and Frost filtered images), and one representing textural attributes (coefficient of variation and $\alpha$ parameter images). With this procedure, the best result was achieved when the Frost and the $\alpha$ parameter filtered images were used.

In this work, the classification algorithm used was the multivariate ICM, considering neighbourhood of eight pixels [3]. The hypothesis of normality for all classes were assumed.

Aiming at the comparison of the classification results between JERS-1 and RADARSAT images, the classification procedure was initiated using only the two attributes that gave best performance in [7] (Frost and $\alpha$ parameter). The results of classification were evaluated by computing the Kappa coefficient of agreement using test samples. The test and training samples were previously selected based on a field information performed in 1996.

\section{RESULTS AND CONCLUSIONS}

It can be seen from Fig. la and $1 \mathrm{c}$ that the tonal information is probably not enough to separate primary from secondary forest. Recent activities appears darker than the two other classes. The used textural attribute (Fig $1 \mathrm{~d}$ and 1e), however, does carry information in RADARSAT images. The $\alpha$ values are larger for secondary forest and recent activities than for primary forest, showing that the two former classes are more homogeneous (smoother) than the later class for $\mathrm{C}$ band. This fact is not seen when JERS-1 image is used.

Fig. $2 \mathrm{a}$ and $2 \mathrm{~b}$ show the results of classification for JERS-1 and RADARSAT images, respectively, and Tables 1 and 2 present the corresponding confusion matrices. The numbers in these matrices refer to the number of pixels and their corresponding percentages. The Kappa coefficients of agreement and their variance associated to these tables are 0.30 $\left(4.17 \times 10^{-5}\right)$ and $0.72\left(1.74 \times 10^{-5}\right)$. From the analysis of Fig. $2 \mathrm{a}$ and the Table 1, it can be observed that, using JERS-1 image, only recent activities may be well discriminated, and there are great confusion is between primary and secondary forest. From the analysis of Fig. $2 b$ and the confusion matrix given in Table 2 it can be concluded that, using RADARSAT image, it might be possible to separate the three classes when tonal and textural information are used together. However, there is some confusion between recent activities and secondary forest using RADARSAT image.

It can be concluded that the RADARSAT image is a better choice if the objective is to discriminate secondary from primary forest. However, if the aim is to discriminate recent activities, JERS-1 image is more useful than RADARSAT image. This fact is important, since the detection of recent deforestation in Amazon is a very relevant information for actions to be taken by the Brazilian government.

Table 1: Confusion matrix of JERS-1 classification.

\begin{tabular}{|c|c|c|c|c|}
\hline True/Class. & RecAct. & SecFor. & PriFor. & Total \\
\hline RecAct. & $10791(99.5)$ & $21(0.2)$ & $28(0.3)$ & 10840 \\
\hline SecFor. & $4(0.1)$ & $3452(79.0)$ & $914(20.9)$ & 4370 \\
\hline PriFor. & $99(0.2)$ & $30744(62.8)$ & $18110(37.0)$ & 48953 \\
\hline Total & 10894 & 34217 & 19052 & 64163 \\
\hline
\end{tabular}

Table 2: Confusion matrix of RADARSAT classification.

\begin{tabular}{|c|c|c|c|c|}
\hline True/Class. & RecAct. & SecFor. & PriFor. & Total \\
\hline RecAct. & $13013(77.4)$ & $3165(18.8)$ & $628(3.8)$ & 16806 \\
\hline SecFor. & $973(13.0)$ & $3677(49.2)$ & $2831(37.8)$ & 7481 \\
\hline PriFor. & $683(1.4)$ & $1587(3.2)$ & $47290(95.4)$ & 49560 \\
\hline Total & 14669 & 8429 & 50749 & 73847 \\
\hline
\end{tabular}

\section{REFERENCES}

[1] A. Beaudoin, T. LeToan, C.C. Hsu, H.C. Han, J. A. Kong, R. T. Shin. Simulation of forest backscatter as a function of forest and ground parameters. In IGARSS'92 Proceedings, Houston, TX, 26-29 May, vol. 2, p. 12121214, 1992.

[2] A.C. Frery, H.J. Müller, C.C.F. Yanasse and S.J.S. Sant'Anna. A model for extremely heterogeneous clutter. IEEE Transactions on Geoscience and Remote Sensing, 35(3):648-659, 1997.

[3] A.C. Frery, C.C.F. Yanasse, P.R. Vieira, S.J.S. Sant'Anna and C.D. Rennó. A user-friendly system for synthetic aperture radar image classification based on grayscale distributional properties and context. Simpósio Brasileiro de Computação Gráfica e Processamento de Imagens, 10., 1997, p. 211-218. SIBGRAPI 97. Los Alamitos, CA, IEEE Computer Society, 1997.

[4] INSTITUTO NACIONAL DE PESQUISAS ESPACIAIS (INPE). INPE atualiza os dados do desflorestamento na Amazônia, de 95 a 97. INPE Notícias, 13, 1998.

[5] T. LeToan, A. Beaudoin, J. Riom and D. Guyon. Relating forest biomass to SAR data. IEEE Transactions on Geoscience and Remote Sensing, 30:403-411, 1992. 
[6] A.J. Luckman, J. Baker, T.M. Kuplich, C.C.F. Yanasse and A.C. Frery. A study of the relationship between radar backscatter and regenerating tropical forest biomass for spacebom SAR instruments. Remote Sensing of Environment, 60:1-13, 1997.

[7] S.J.S. Sant'Anna, C.C.F. Yanasse and A.C. Frery. Estudo comparativo de alguns classificadores utilizando-se imagens RADARSAT da região de Tapajós. In Proceedings of the First Latino-American Seminar on Radar Remote Sensing - Image Processing Techniques, (ESA SP-407), Buenos Aires, Argentina, Dez 1996, p. 187-194, 1997.

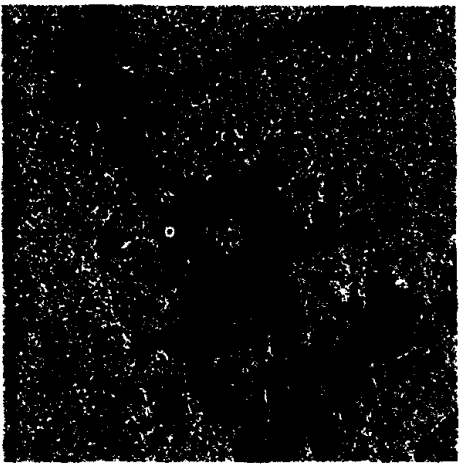

(a)

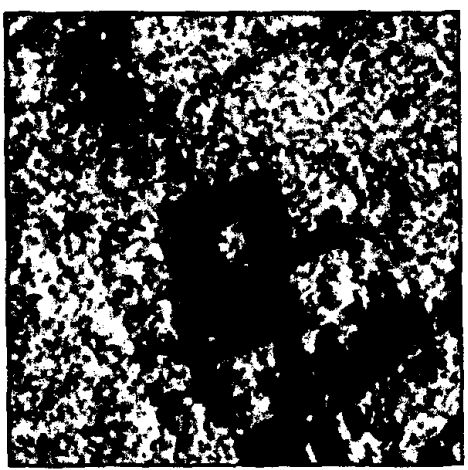

(d)

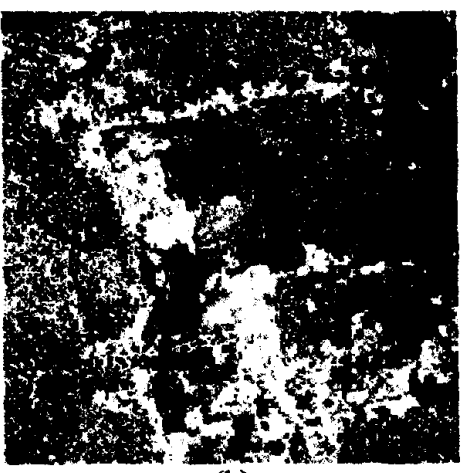

(b)

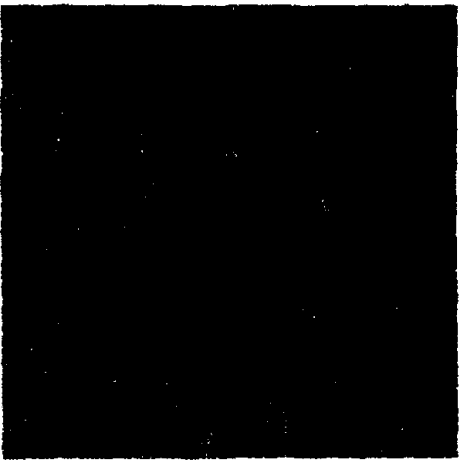

(c)

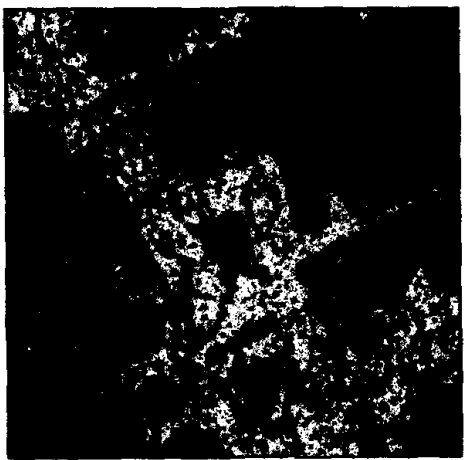

(e)

Figure 1: (a) JERS-1 original, (b) LandsatTM, (c) RADARSAT original, (d) JERS-1 $\alpha$ filtered and (e) RADARSAT $\alpha$ filtered images.

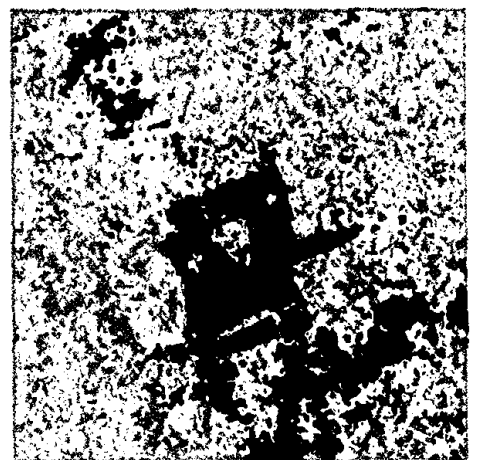

(a)

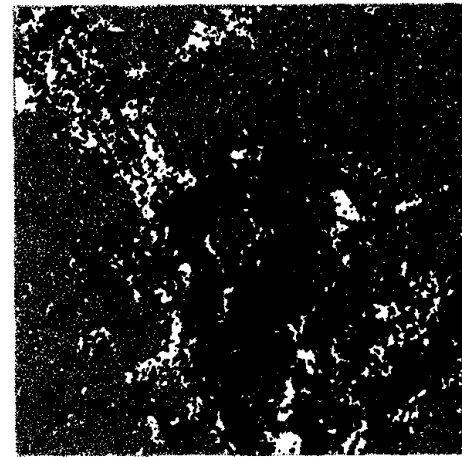

(b)

Figure 2: (a) JERS-1 and (b) RADARSAT classification images. 